\title{
PENGGUNAAN METODE INKUIRI (MI) DALAM PEMBELAJARAN BIOLOGI UNTUK SISWA KELAS VII SMPLB TUNARUNGU SEKOLAH LUAR BIASA (SLB) - KARTINI BATAM
}

\section{THE APPLICATION OF INQUIRY METHOD ON LEARNING BIOLOGY FOR DEAF STUDENTS AT EXTRAORDINARY SCHOOL AT GRADE VII SMPLB SLB - KARTINI BATAM}

\author{
Riniatun Riniatun ${ }^{1}$, Notowinarto Notowinarto ${ }^{*}{ }^{2}$, Fenny Agustina ${ }^{3}$ \\ ${ }^{1,2,3}$ Program Studi Pendidikan Biologi, FKIP, Universitas Riau Kepulauan, Batam \\ *Koresponden: notowinarto@yahoo.co.id
}

\begin{abstract}
Abstrak
Penelitian ini bertujuan untuk mengetahui apakah pendekatan model Inkuiri (MI) dapat meningkatkan motivasi belajar siswa dalam mata pelajaran ilmu pengetahuan alam (IPA). Serta apakah ada hubungan antara pengaruh pendekatan MI dengan pendekatan Model Konvesional (MK) dalam pembelajaran IPA terhadap prestasi belajar siswa gangguan pendengaran di kelas VII di SMPLB TUNARUNGU SLB-KARTINI KOTA BATAM Tahun Ajaran 2012/2013. Penelitian ini menggunakan rancangan model pendekatan Single Subject Research (SSR) yang merupakan sarana eksperimen semu (quasi), dengan subyek materi menggunakan multimedia sebagai intervensi dan perilaku untuk pemahaman konsep pembelajaran MI (Poedjiastoeti dan Liliasari. 2010). Hasil penelitian menunjukkan bahwa nilai diskriptif pretes-postes pada perlakuan pembelajaran metode konvesional dengan model inkuiri nilai dengan selisih interval adalah 14.33 untuk prestes dan 7.0 untuk postes serta rerata materi bahasan pretes dengan nilai tertinggi pada materi bahasan Ekskresi dan terendah Nafas serta untuk nilai postest pada materi bahasan sama yaitu Ekskresi sebagai nilai terendah dan tertinggi pada Gerak. Hasil $u j i-t$ menunjukkan adanya indikasi beda rata-rata nilai yang beda dan signifikan antar perlakuan model pembelajaran yang menunjukkan perbedaan nyata positip hanya 2 (dua) topik materi adalah rangsang dan habitat. Sedangkan $U j i F$ pretes - postes 10 item bahasan antar nilai siswa menunjukkan signifikan (S, nyata), sedangkan untuk nilai antar model pembelajaran menunjukkan tidak signifikan (NS, tidak nyata).
\end{abstract}

Kata Kunci: Model Inkuiri, Model Konvesional, Ciri-ciri Mahkluk hidup, Uji t, Uji F.

\begin{abstract}
This study aims to determine whether inquiry approach can increase students' motivation on learning science. As well as whether there is a correlation between the effect of inquiry approach with an conventional approach on learning science toward deaf student's achievement grade VII at SMPLB DEAF SLB-KARTINI CITY BATAM Academic Year 2012/2013. This study used Single Subject Research (SSR), which is quasi-experimental with the subject matter using multimedia as behavioral interventions and for understanding the concept of learning MI (Poedjiastoeti and Liliasari. 2010). The results showed that pretest-posttest value description on the conventional method treatment and inquiry method was 14:33 for Pretest interval differences and 7.0 for post-test with mean subject matter pretest with the highest value on the subject matter Excretion and lows Breath as well as to the value of post-test on the material the same discussion that Excretion as the lowest and highest value on the Motion. The results of t-test showed any indication of the average difference value and significant difference between treatments learning model that shows positive real differences only two (2) subject matter is excitatory and habitat. While the F test pretest - posttest 10 items of discussion among students showed significant values $(S$, real), while the value of inter-learning models show no significant (NS, not real).
\end{abstract}

Key Words : Inquiry models, Convesional model, The characteristic of living, t-test, Ftest 


\section{PENDAHULUAN}

Pada pasal 8 ayat (1) UU No. 2 tahun 1989 disebutkan bahwa warga negara yang memiliki kelainan fisik dan atau mental berhak memperoleh Pendidikan Luar Biasa (PLB). Pendidikan Luar Biasa (PLB) adalah pendidikan yang khusus diselenggarakan bagi peserta didik yang menyandang kelainan fisik, mental, perilaku atau gabungan diantaranya. Lebih lanjut berdasarkan PP RI No. 27 tahun 1991 tentang PLB disebutkan yaitu terdiri atas kelainan fisik yang meliputi tuna netra, tuna rungu, tuna daksa. Kelainan mental yang meliputi tuna grahita ringan, tuna grahita sedang, kelainan perilaku yaitu tuna laras atau gabungan diantaranya. Mereka akan dididik dalam satuan pendidikan yang berbentuk TK Luar Biasa, SD Luar Biasa, SLTP Luar Biasa, SM Luar Biasa atau bentuk lain yang ditetapkan oleh Menteri Pendidikan.

Tujuan PLB yaitu: (1) mengembangkan kehidupan anak didik dan siswa sebagai berkepribadian yang mantap dan mandiri; (2) memperkuat kesadaran hidup beragama dalam masyarakat, menumbuhkan rasa tanggung jawab dalam lingkungan hidup, memberikan pengetahuan dan keterampilan dasar untuk berperan serta dalam kehidupan bermasyarakat;(3) mempersiapkan siswa untuk dapat memiliki keterampilan sebagai bekal untuk memasuki dunia kerja dan (4) mempersiapkan anak didik dan siswa untuk mengikuti pendidikan lanjutan dalam menguasai isi kurikulum yang disyaratkan (Kurnaeni, 2009). Siswa tuna rungu di SLB B umumnya mendapat pengajaran dengan sistem komunikasi oral, yakni menekankan pada proses pengembangan bahasa melalui metode percakapan untuk semua mata pelajaran.

Metodologi pengajaran bahasa bagi Anak Tunarungu dasar konsep komunikasi ditetapkan atas dasar individual, yakni dengan 4 (empat) pendekatan metode dalam pembelajaran bahasa, yaitu: a) dengan membaca ujaran (Speechreading); b) melalui pendengaran (Auditori verbal ); c) dengan komunikasi manual (Auditori Oral); dan d) dengan kombinasi ketiga cara tersebut. Kualitas komunikasi verbal anak dengan gangguan pendengaran biasanya ditambah dengan penggunaan bahasa ujaran isyarat (Cued Speech) yang merupakan isyarat tambahan dengan gerakan tangan atau bibir untuk melengkapi membaca ujaran untuk berkomunikasi di antara sesama (Maryati. 2009).

Konsep pembelajaran metode inkuiri (MI) adalah suatu proses pembelajaran untuk memperoleh dan mendapatkan informasi dengan melakukan observasi dan atau 
eksperimen guna mencari jawaban atau memecahkan masalah dengan menggunakan kemampuan berpikir kritis dan logis serta memiliki motivasi tinggi dalam upaya memahami fenomena alam, memperjelas pemahaman, dan menerapkannnya dalam kehidupan sehari-hari, sehingga peserta didik dibiasakan untuk produktif, analitis dan kritis (Roestiyah, 2008).

Penelitian ini dibatasi pada pengkajian dan pengamatan atas pengaruh penerapan metode inkuiri (MI) terhadap perbedaan dengan metode konvensial teoritis (MK) yang biasa dilakukan. Bertujuan untuk mengetahui apakah pendekatan MI dapat meningkatkan motivasi belajar siswa dalam mata pelajaran ilmu pengetahuan alam (IPA). Serta apakah ada hubungan antara pengaruh pendekatan MI dengan pendekatan MK dalam pembelajaran IPA terhadap prestasi belajar siswa gangguan pendengaran di kelas VII SMPLB

\section{METODOLOGI}

Penelitian ini menggunakan rancangan model Single Subject Research (SSR) yang merupakan sarana eksperimen semu (quasi), dengan subyek materi menggunakan multimedia sebagai intervensi dan perilaku untuk pemahaman konsep pembelajaran MI (Poedjiastoeti dan Liliasari. 2010). Sedangkan model rancangan untuk terapan MK dan MI mengacu pada proses 4 siklus yang terdiri dari 4 tahapan, yaitu : (1) penyusunan rencana tindakan; (2) pelaksanaan tindakan; (3) pengamatan; dan (4) perefleksian, pengambilan kesimpulan dan saran. Subjek penelitian dilakukan terhadap 3 (tiga) siswa KELAS VII SMP-LB KARTINI BATAM dengan pertimbangan dari hasil observasi awal terlihat bahwa kurangnya motivasi belajar siswa dalam menerima mata pelajaran IPA-Biologi dengan pokok bahasan "Ciri-ciri Mahkluk Hidup” meliputi 10 topik materi yaitu: Bernapas; Bergerak; Menerima dan mereaksi rangsang; Memerlukan makanan; Tumbuh dan berkembang; Berkembang biak; Mengeluarkan zat sisa; Melakukan adaptasi; Memerlukan habitat tertentu; Pertumbuhan dan perkembangan manusia atau mahluk hidup lainnya.

Prosedur pengumpulan data sebagai berikut : a) Pengamatan pendahuluan dilakukan observasi non sistematis (tidak menggunakan instrumen) untuk mengidentifikasi masalah; b) Teknis pengumpulan data menggunakan metode eksperimen dengan pendekatan Single Subject Research $(S S R)$ adalah A-B-A-B, yaitu 
desain penelitian yang memiliki empat fase yaitu; A-1 (baseline-1), B-1 (intervensi-1), A-2 (baseline-2) dan B-2 (intervensi-2), masing masing dengan instrument pilihan berganda khusus yang dikonsultasi dan divalidasi secara internal; c) Data primer berupa hasil pre-tes dan pos-tes siswa dalam proses pembelajaran untuk mengetahui tingkat pemahaman dan aplikasi konsep serta penalaran, pemahaman dan pengetahuan siswa terhadap konsep. Instrumen tes berupa pilihan berganda dengan jumlah 20 butir dan 4 pilihan jawaban ( $a, b, c, d$ ), yang sebelumnya instrumen tersebut telah uji validitasi meliputi validitas isi dan validitas konstruk yang dilakukan oleh para guru senior. Validitas butir soal tes dengan menggunakan Point Biserial Correlation $\left(\mathrm{r}_{\mathrm{pbis}}\right)$ (Sudjana, N. 2005) serta uji reliabilitas memakai Alfa Cronbach $\left(\mathrm{KR}_{20}\right)$ (Arikunto, S. 2008).

Analisa prasyarat data yakni Uji Normalitas menggunakan uji Chi Kuadrat $\left(\chi^{2}\right)$ dan Uji Homogenitas. d) Pengujian hipotesis membandingkan MK dengan MI dengan pendekatan menggunakan statistik Nonparametris Mann-Whitney U-Test pada taraf signifikan $\alpha=0,05$. Data pre-tes dan pos-tes bila harga $U_{2}$ lebih besar dari $U_{1}$, kemudian membandingkan dengan $U_{\text {tabel }}$ adalah $U_{2}$ maka akan dilakukan pengujian satu pihak. Apabila harga $U_{\text {hitung }}$ lebih kecil dari $U_{\text {tabel }}$ maka $\mathrm{H}_{0}$ ditolak dan $\mathrm{H}_{\mathrm{a}}$ diterima, demikian sebaliknya.

\section{PEMBAHASAN}

Perubahan nilai yang cukup baik dari perlakuan proses model pembelajaran yang diberikan, semuanya cenderung meningkat, serta dari nilai tersebut sepertinya materi ekskresi merupakan bahasan yang cukup berat pemahamannya bagi siswa SLB.

Tabel 1. Rekapitulasi nilai diskriptif data hasil pretes - postest tiap materi bahasan

\begin{tabular}{lcc}
\hline Materi Bahasan & Rerata Nilai Pretes & Rerata Nilai Postes \\
\hline 1. Nafas & 53.00 & 75.00 \\
2. Gerak & 61.00 & 75.33 \\
3. Rangsang & 60.33 & 74.67 \\
4. Kemb. Biak & 67.33 & 74.33 \\
5. Makanan & 60.00 & 71.33 \\
6. Pertumbuhan & 58.33 & 69.33 \\
7. Adaptasi & 59.33 & 70.33 \\
8. Regulasi & 59.33 & 68.67 \\
9. Eksresi & 63.00 & 68.33 \\
10. Habitat & 61.33 & 74.00 \\
\hline
\end{tabular}


Tabel 2. Rekapitulasi nilai diskriptif data hasil pretes - postest

\begin{tabular}{|c|c|c|}
\hline Parameter & Pretes & Postes \\
\hline Mean & 60.30 & 72.13 \\
\hline Standard Error & 1.14 & 0.89 \\
\hline Median & 60.17 & 72.67 \\
\hline Mode & 59.33 & 74.00 \\
\hline Standard Deviation & 3.61 & 2.82 \\
\hline Sample Variance & 13.05 & 7.93 \\
\hline Kurtosis & 2.53 & -2.00 \\
\hline Skewness & -0.09 & -0.22 \\
\hline Range & 14.33 & 7.00 \\
\hline Minimum & 53.00 & 68.33 \\
\hline Maximum & 67.33 & 75.33 \\
\hline Sum & 603.00 & 721.33 \\
\hline Count & 10.00 & 10.00 \\
\hline Largest(1) & 67.33 & 75.33 \\
\hline Smallest $(1)$ & 53.00 & 68.33 \\
\hline Confidence Level(95.0\%) & 2.58 & 2.01 \\
\hline
\end{tabular}

Pada Tabel 1 dan 2 maka terlihat bahwa nilai diskriptif pretes - postes dengan nilai rerata minimal maksimal prestes 53.00 - 67.33, sedangkan postes $68.33-75.33$ masing dengan selisih interval adalah 14.33 untuk prestes dan 7.0 untuk postes. Sedangkan pada rerata materi bahasan pretes dengan nilai tertinggi pada materi bahasan Ekskresi (63.00) dan terendah Nafas (53.00) serta untuk nilai postest pada materi bahasan sama yaitu Ekskresi (68.33) sebagai nilai terendah dan tertinggi pada Gerak (75.33).

Model pembelajaran pada setiap bahasan materi dengan 2 (dua) model perlakuan berbeda baik nilai rerata, nilai kinerja siswa maupun total nilai maka telah terjadi perubahan nilai atas perlakuan tersebut, yakni; model pembelajaran konvesional (MK) untuk pretes dengan nilai 112.47 dan nilai postes dengan inkuiri (MI) adalah 141.33 telah terjadi perbedaan yang cukup nyata yaitu sebesar kurang lebih 17 point. Maknanya bahwa siswa nampaknya menyukai dan mudah memahami model pembelajaran inkuiri (MI) yang disampaikan melalui media gambar menggunakan infokus.

Uji statistik dengan Uji T paired adalah membandingkan nilai-nilai pretes postes yang diperoleh dari siswa yang sama. Kemudian lebih lanjut juga dibandingkan dengan hasil rata2 dari 10 item tes (Bernapas; Bergerak; Menerima dan mereaksi rangsang; Memerlukan makanan; Tumbuh dan berkembang; Berkembang biak; Mengeluarkan zat sisa; Melakukan adaptasi; Memerlukan habitat tertentu; Pertumbuhan dan perkembangan manusia atau mahluk hidup lainnya) dengan pendekatan uji Anova. 
Hasil analisis uji-t berpasangan (t-test paired sample) dan Anova dari setiap materi kompetensi dasar (KD) sebanyak 10 tes disajikan pada Table 3.

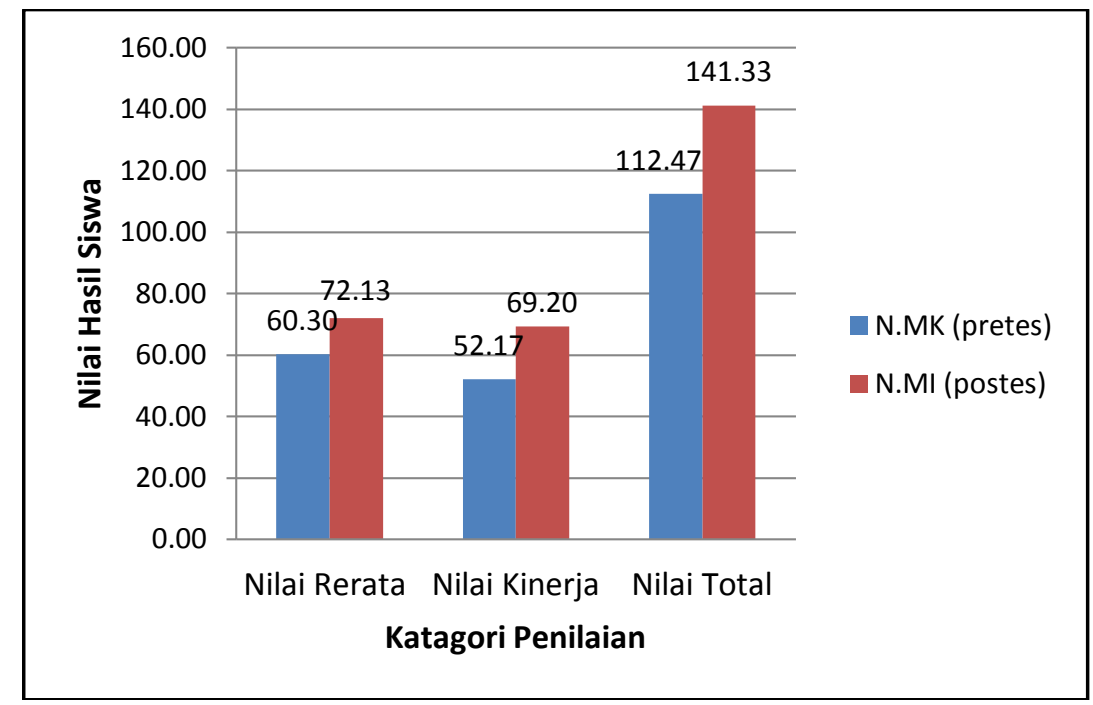

Gambar 1. Rekapitulasi Hasil Perbandingan Nilai Metode Konvensial (N.MK) dengan Nilai Metode Inkuiri (N.MI)

Tabel 3. Rekapitulasi Hasil Uji Beda (Uji t-test) data pretes - postes KD materi Ciri-ciri Mahkluk Hidup

\begin{tabular}{|c|c|c|c|c|c|c|c|c|}
\hline \multirow{3}{*}{$\begin{array}{c}\text { Topic } \\
\text { Ciri2 } \\
\text { Mahkluk } \\
\text { Hidup }\end{array}$} & \multicolumn{5}{|c|}{ Paired Differences } & \multirow{3}{*}{$\mathbf{t}$} & \multirow{3}{*}{ df } & \multirow{3}{*}{$\begin{array}{c}\text { Significan } \\
\text { (2-tailed)/ } \\
\text { Remark } \\
\text { (Sig; NSig) }\end{array}$} \\
\hline & \multirow[t]{2}{*}{ Mean } & \multirow[t]{2}{*}{$\begin{array}{c}\text { Std. } \\
\text { Deviation }\end{array}$} & \multirow{2}{*}{$\begin{array}{l}\text { Std. } \\
\text { Error } \\
\text { Mean }\end{array}$} & \multicolumn{2}{|c|}{$\begin{array}{l}95 \% \text { Confidence } \\
\text { Interval } \\
\text { of the Difference }\end{array}$} & & & \\
\hline & & & & Lower & Upper & & & \\
\hline Nafas & -22.000 & 11.533 & 6.658 & -50.648 & 6.648 & -3.304 & 2 & 0.081/Nsig. \\
\hline Gerak & -14.333 & 3.214 & 1.856 & -22.319 & -6.348 & -7.723 & 2 & 0.016/Nsig. \\
\hline Rangsang & -14.333 & 0.577 & 0.333 & -15.767 & -12.89 & 43.00 & 2 & $0.001 /$ Sig. \\
\hline Kem.biak & -7.000 & 6.083 & 3.512 & -22.110 & 8.110 & -1.993 & 2 & $0.184 / \mathrm{Nsig}$. \\
\hline Makanan & -11.333 & 6.351 & 3.667 & -27.109 & 4.443 & -3.091 & 2 & $0.091 /$ Nsig. \\
\hline Tumbuh & -11.000 & 5.196 & 3.000 & -23.907 & 1.907 & -3.667 & 2 & 0.067/Nsig. \\
\hline Adaptasi & -11.000 & 5.196 & 3.000 & -23.907 & 1.907 & -3.667 & 2 & 0.067/Nsig. \\
\hline Regulasi & -9.333 & 5.859 & 3.383 & -23.889 & 5.222 & -2.759 & 2 & $0.110 /$ Nsig. \\
\hline Ekskresi & -5.333 & 3.214 & 1.856 & -13.319 & 2.652 & -2.874 & 2 & 0.103/NSig. \\
\hline Habitat & -12.666 & 0.577 & 0.333 & -14.101 & -11.23 & 38.00 & 2 & $0.001 /$ Sig. \\
\hline Rerata & -11.833 & 2.003 & 1.157 & -16.809 & -6.857 & -10.23 & 10 & 0.009/Sig. \\
\hline
\end{tabular}

Pada tabel 3 dari 10 item topik materi maka hasil uji-t menunjukkan adanya indikasi beda rata-rata nilai. Materi bahasan kompetensi dasar ciri-ciri makhluk hidup yang menunjukkan perbedaan nyata positip hanya 2 (dua) topik materi adalah rangsang dan habitat. Namun apabila dirata-rata maka total 10 item pokok bahasan menunjukkan indikasi ada perbedaan dari kondisi 2 perlakuan model pembelajaran. Hal terjadi diduga karena kecenderungan siswa SLB cepat bosan menghadapi sesuatu yang membutuhkan 
logika kognitif secara terus menerus, diperlukan selingan bentuk-bentuk permainan yang mudah dan aktratif. Hal ini terbukti pada hasil menggunakan uji $\mathrm{F}$ (tabel 4) pretes - postes 10 item bahasan antar nilai siswa menunjukkan $F_{\text {hitung }}(5,565)>F_{\text {tabel }}(2.456)$ yang signifikan (S, nyata), sedangkan untuk nilai antar model pembelajaran menunjukkan $F_{\text {hitung }}(1.805)<F_{\text {tabel }}$ (3.554) tidak signifikan (NS, tidak nyata).

Tabel 4. Hasil Uji F seluruh nilai pretes - postes KD materi Ciri-ciri Mahkluk Hidup

\begin{tabular}{lrrrrrc}
\hline Source of Variation & \multicolumn{1}{c}{$S S$} & \multicolumn{1}{c}{$d f$} & \multicolumn{1}{c}{$M S$} & \multicolumn{1}{c}{$F$} & P-value & F crit \\
\hline Rows & 352.3 & 9 & 39.14444 & 5.565561 & 0.000992 & 2.456281 \\
Columns & 25.4 & 2 & 12.7 & 1.805687 & 0.192891 & 3.554557 \\
Error & 126.6 & 18 & 7.033333 & & & \\
\hline Total & $\mathbf{5 0 4 . 3}$ & $\mathbf{2 9}$ & & & & \\
\hline
\end{tabular}

\section{KESIMPULAN}

Nilai diskriptif pretes - postes pada perlakuan pembelajaran metode konvesional dengan model inkuiri nilai dengan selisih interval adalah 14.33 untuk prestes dan 7.0 untuk postes. Sedangkan pada rerata materi bahasan pretes dengan nilai tertinggi pada materi bahasan Ekskresi (63.00) dan terendah Nafas (53.00) serta untuk nilai postest pada materi bahasan sama yaitu Ekskresi (68.33) sebagai nilai terendah dan tertinggi pada Gerak (75.33).

Hasil uji-t menunjukkan adanya indikasi beda rata-rata nilai yang berda dan signifikan antar perlakuan model pembelajaran yang menunjukkan perbedaan nyata positip hanya 2 (dua) topik materi adalah rangsang dan habitat. Sedangkan pada hasil menggunakan uji $F$ pretes - postes 10 item bahasan antar nilai siswa menunjukkan $F_{\text {hitung }}(5,565)>F_{\text {tabel }}(2.456)$ yang signifikan $(S$, nyata), sedangkan untuk nilai antar model pembelajaran menunjukkan $F_{\text {hitung }}(1.805)<F_{\text {tabel }}$ (3.554) tidak signifikan (NS, tidak nyata). Sehingga dapat disimpulkan bahwa tidak beda nyata 2 (dua) model perlakuan antara model konvesional dengan model inkuiri adalah sama.

\section{REFERENSI}

Aprilia I.D dan P.R. Lestari, 2006. Penerapan Pendekatan Multi dalam Meningkatkan Kemampuan Menghafal Bacaan Sholat pada Anak Tunarungu pada Siswa Tunarungu Kelas VI SDLB SLB B Sukapura - Bandung. Jurusan Pendidikan Luar Biasa FIP UPI, Bandung. 
Asniarno, F., 2009. Pengaruh Gerak Dasar pada Pendidikan Jasmani Adaptif dalam Meningkatkan Kemampuan Motorik Anak Tuna Rungu DI SLB B/C Yayasan Pembina Sekolah Luar Biasa (YPSLB) Kartasura Tahun. Jurusan Ilmu Pendidikan Universitas Sebelas Maret, Solo.

Efendi, M., Triaswati, E dan P. Hariyanto, 2008. Penggunan Media Ceritera Bergambar Berbasis Pedekatan Komunikasi Total untuk Meningkatkan Kemampuan Bahasa Anak Tunarungu Kelas Rendah Di SLB Bagian B YPTB Malang UNIBRA Malang.

Kurnaeni. 2009. Metode Pengajaran Bahasa Bagi Anak Tunarungu "Klasifikasi dan Jenis Ketunarunguan serta Metode Pengajaran Bahasa Bagi Anak Tunarungu” Administrator Dinas Pendidikan Luar Biasa Provinsi Jawa Barat. Seminar Parenting Support I-CHAT/AKRAB, Jakarta.

Mangunsong, F., 2009. Mempersiapkan Anak Tuna Rungu Menuju Sekolah: Psikologi dan Pendidikan Anak Berkebutuhan Khusus. Cetakan Pertama, LPSP3 UI, Jakarta.

Nurkolis, 2009. Reformasi Kebijakan Pendidikan Luar Biasa. Seminar Parenting Support I-CHAT/AKRAB, Jakarta.

Poedjiastoeti, S dan L. Liliasari, 2010. Pembelajaran Kimia Berbantuan Multimedia untuk Siswa Tunarungu SMALB-B. Jurnal Ilmu Pendidikan (JIP) Vol 17, No 1

Rahmad, D., 2006. Pengembangan Model Pembelajaran Maternal Reflektif Untuk Meningkatkan Kemampuan Berkomunikasi Anak Tuna Rungu Di Sekolah Dasar. Jurusan Ilmu Pendidikan - Universitas Pendidikan Indonesia, Bandung.

Roestiyah, 2009. Model Latihan Inkuiri. Makalah Workshop Guru Pemandu di LPMP Semarang.

Sudiyono, Anas. 2005. Pengantar Statistik Pendidikan. PT. Raja Grafindo Persada, Jakarta.

Sumarto, 2009. Metode Baru untuk Anak-anak Tuna Rungu. Seminar Parenting Support I-CHAT/AKRAB, Jakarta.

Suparno, 2007. Pendidikan anak Berkebutuhan Khusus. Bahan Ajar Cetak. Direktorat Jenderal Pendidikan Tinggi. Departemen Pendidikan Nasional. 